\title{
DNA damage levels in systemic lupus erythematosus patients with low disease activity: An evaluation by comet assay
}

\author{
Thaís Muniz Montalvão 1,2, Ana Luisa Miranda-Vilela ${ }^{3}$, Mariana Matos Roll², Cesar Koppe Grisolia², \\ Leopoldo Santos-Neto ${ }^{1,4}$ \\ ${ }^{1}$ University Hospital of Brasília, University of Brasília, Brasília, Brazil \\ ${ }^{2}$ Laboratory of Genetic Toxicology, Institute of Biological Sciences, University of Brasília, Brasília, Brazil \\ ${ }^{3}$ Department of Genetics and Morphology, Laboratory of Genetics, Institute of Biological Sciences, University of Brasilia, Brasilia, \\ Brazil \\ ${ }^{4}$ Faculty of Medicine, University of Brasilia, Brasília, Brazil \\ Email: thaismunizms@gmail.com
}

Received 1 August 2012; revised 12 September 2012; accepted 17 October 2012

\begin{abstract}
Oxidative stress has been implicated in the inflammatory process of Systemic Lupus Erythematosus (SLE), particularly by the formation of anti-DNA autoantibodies, which can lead to DNA damage. The aim of this study was to investigate, through comet assay, whether the level of DNA damage in SLE patients is different from that of healthy subjects. Twenty-five adult SLE patients with SLEDAI up to ten, and 25 healthy subjects were paired according to age, gender and Body Mass Index (BMI). Other anthropometric variables were also assessed. Comet assay was assessed as the marker of oxidative stress described as DNA Damage (DD) percentage. Waist Circumference (WC), Hip Circumference (HC) and BMI were also performed. Exclusion criteria for patients and controls comprised smoking and other chronic disorders. Level of damage index was remarkably higher in SLE patients than in controls, and no significant differences between the groups were found for age, BMI, WC and HC. No stratification concerning gender was performed, since there were just two males per group. No correlation was observed between BMI and DD (\%). DD increased in SLE, which reflects the oxidant/antioxidant imbalance in these patients. These findings support an association between oxidative stress and SLE. This stronger correlation observed in patients with low disease activity may be useful in elucidating the mechanisms of disease pathogenesis.
\end{abstract}

Keywords: Systemic Lupus Erythematosus; DNA Damage; Comet Assay; Oxidative Stress

\footnotetext{
"Corresponding author.
}

\section{INTRODUCTION}

Systemic Lupus Erythematosus (SLE) is a chronic autoimmune disease that predominantly affects women of reproductive age $[1,2]$. It is caused by the interaction of genetic, hormonal and environmental factors leading to dysfunction of T-cells, B-cells, and dendritic cells with the production of antinuclear autoantibodies [3-5] that are deposited on several organs, including kidneys, skin and joints, causing inflammation [2]. So, SLE is characterized by inappropriate immune response to self-antigens and periods of high activity and remission [6].

Pro-oxidants are molecules with a single unpaired electron, known as a free radical, which have the potential to damage healthy cells [7]. Uncontrolled increases in the generation of free radicals exceed the capacity of antioxidant mechanisms to defend against them, resulting in oxidative stress with damage to lipids, proteins and DNA [8]. This process contributes to chronic inflammation of tissues and causes immunomodulation that can lead to autoimmune diseases such as SLE [3]. Thus, the cause of oxidative stress in SLE patients is excessive production of free radicals and other reactive oxygen/ nitrogen/chlorine species $[3,9]$. The action of free radicals leads to the formation of protein carbonyls, 3-nitrotyrosine and protein hydroperoxide. The protein thiol group can inhibit hydroperoxide formation of protein by the removal of peroxyl radical. The levels of protein carbonyl, 3-nitrotyrosine and the protein thiol groups may reflect approximately the total level of protein oxidation in LES [10]. Oxidized proteins also cause physiological disorders. Changes in amino acid sequence or structure may generate neo-epitopes of proteins themselves, causing an aggressive autoimmune attack. The oxidation causes post-translational modifications of pro- 
teins which allow recognition of new epitopes stimulating $B$ cells and/or $T$ cells which lead to a break in tolerance [4].

Lipid peroxidation leads to formation of highly reactive aldehydes such as malondialdehyde (MDA) and 4-hydroxynonenal (HNE), which can bind to proteins and thus result in a structural change and affect their biological functions. Increases in oxidative stress and the formation of MDA and HNE are associated with SLE [5, 11]. However, these oxidative responses are not correlated to the disease activity or its duration [9].

The susceptibility to oxidative stress can be also influenced by genetic polymorphisms of antioxidant enzymes such as superoxide dismutase (SOD), catalase (CAT), and glutathione peroxidase (GPx), as well as endogenous levels of antioxidants such as L-ascorbic acid and $\alpha$-tocopherol and glutathione levels [12]. Furthermore, the inflammation per se can induce an oxidative stress response so that the pathways form a vicious circle of oxidative stress and inflammation [13]. Besides, medications used in SLE worsen the oxidant/antioxidant imbalance [3].

Comet assay or single cell gel electrophoresis is a rapid, simple, visual and sensitive technique widely used to measure and analyze DNA breakage in mammalian cells $[14,15]$. This methodology was developed in the mid 1980s by Östling and Johanson for direct visualizetion of DNA damage in individual cells [14]. Later, Singh et al. modified this technique by carrying out the electrophoresis at an alkaline $\mathrm{pH}$ [15] with the main focus on maximizing the sensitivity of detection of low levels of DNA damage [16]. Although this is not the only way to measure oxidatively damaged DNA, it is one of the most sensitive and accurate [17] and has been considered a valuable tool for population monitoring, for example in assessing the role of oxidative stress in human disease, mechanisms of mutagenesis and genotoxicology, among others [17-20].

Oxidative stress has been evaluated in SLE patients by different methods with conflicting results. No published studies have examined this status in these patients by comet assay. So, the aim of this study was to investigate, through comet assay, whether the level of DNA damage in SLE patients is different from that of healthy subjects.

\section{MATERIALS AND METHODS}

\subsection{Sample Source}

Twenty-five adult SLE outpatients with SLE Disease Activity Index (SLEDAI) [21] up to ten were selected from the rheumatology ward of the University Hospital of Brasília, Federal District, Brazil. As controls, 25 health workers or students from the University of Brasília, Federal District, Brazil, were recruited. They were all over 18 years of age and were paired according to age, gender and BMI, with other anthropometric variables included. SLE patients were diagnosed according to the American College of Rheumatology (ACR) 1997 revised criteria [22] and were in treatment. Exclusion criteria for patients and controls comprised smoking, pregnancy, diabetes, renal failure, active infection, Sjögren Syndrome, angina pectoris, ischemic stroke, SLEDAI above 10 (just for SLE patients) and the use of anti-inflammatory drugs (just for control subjects). The subjects did not receive a specific diet and did not use antioxidant supplements. Demographic and lifestyle information was obtained using an interviewer-administered questionnaire. All subjects signed an informed consent clause and the study protocol was approved by the Ethics Committee of the University of Brasília Medical School, Federal District, Brazil.

\subsection{Comet Assay}

The comet assay (alkali method) was carried out according to Singh et al. (1988) [15], with modifications as previously described $[23,24]$, except that electrophoresis was performed for 30 minutes. One hundred comets on each slide were scored visually as belonging to one of the five classes proposed by Collins et al. (1995) [25]. The number of comets in each category was counted and the DNA damage was calculated according to Jalonszynski et al. (1997) [26], giving a maximum possible score of 400 , corresponding to 100 cells in class 4 . Thus, comet assay was assessed as the marker of oxidative stress described as DNA Damage (DD) percentage. In all cases preliminary experiments were performed to single out the best experimental conditions.

\subsection{Anthropometric Measurements}

Body weight was measured to the nearest $0.1 \mathrm{~kg}$ by using an electronic scale, with subjects wearing light clothing, but no shoes, in the morning. Height was measured to the nearest $0.1 \mathrm{~cm}$ by using a stadiometer, and BMI was calculated as weight $(\mathrm{kg})$ divided by squared height $\left(\mathrm{m}^{2}\right)$. Measures of waist circumference (at the level of the umbilicus) and hip circumference (at the level of maximal gluteal protrusion) were assessed. The waist-hip ratio was determined from waist circumference $(\mathrm{cm})$ divided by hip circumference $(\mathrm{cm})$.

\subsection{Statistical Analysis}

Statistical analysis was performed with the Statistical Package for the Social Sciences version 20 (SPSS Inc., Chicago, USA). Data were presented as means \pm standard deviation (SD) and percentage. KolmogorovSmirnov was performed as normality test. The independent samples $\mathrm{T}$ test was used to compare the mean scores 
(age, BMI, DD\%, WC, HC, W/H ratio and family numbers) of control and SLE groups. The Chi-square test was used to compare the tallies of categorical responses (social drinker and physical activity) between the two groups and Cramer's test was performed when the variables had more than two levels (civil status, occupation, household income, education and skin color). Correlation was performed by Pearson's coefficient (SLEDAI and $\% \mathrm{DD}$ in SLE; BMI and \%DD; W/H ratio and DD (\%) in both groups). P-values were considered significant at $<$ 0.05 .

\section{RESULTS AND DISCUSSION}

Twenty-three SLE females and 2 SLE males as well as 23 control females and 2 control males were studied. Level of damage index was remarkably higher in SLE patients than in controls (Figure 1). This large difference, in spite of the small sample size, can be explained by the persistent oxidative stress and protein oxidation that occurs in SLE patients even with inactive disease or with mild disease activity [4]. Other studies have shown an increase in oxidative stress in SLE patients by using biomarkers-oxidants and antioxidants. Lozovoy et al. (2011) [4] evidenced a significant increase in plasma chemiluminescence, reflecting increased lipid hydroperoxides and decreased antioxidant levels. Zhang et al. (2010) [10] also confirm the presence of oxidative stress in patients with SLE by multiple marker's measurement of protein oxidation. Another study showed significant increases in oxidative and also nitrosative stress in SLE patients, suggesting an imbalance between reactive oxygen and nitrogen species production and antioxidant defense mechanisms in SLE [5]. As far as we know, this is the first study to use the comet assay to evaluate oxidative stress in SLE patients.

The demographic and anthropometric features and DD $(\%)$ in both groups and the SLEDAI in SLE patients are

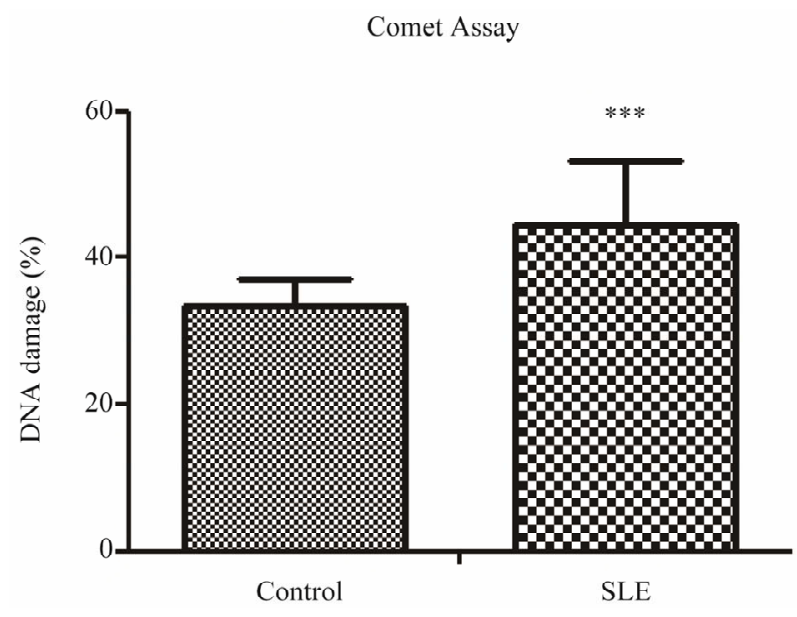

Figure 1. DNA damage index percentage in SLE and controls. shown in Table 1. No significant differences between the groups were found for age, BMI, WC and HC (Table 1). However, there are significant differences for $\mathrm{W} / \mathrm{H}$ ratio and family numbers. $\mathrm{W} / \mathrm{H}$ ratio is related to obesity. Keaney et al. [27] found significantly positive association between indices of obesity, such as BMI and $\mathrm{W} / \mathrm{H}$ ratio, and markers of oxidative stress in the population in general. This association between $\mathrm{W} / \mathrm{H}$ ratio and oxidative stress in postmenopausal women was been demonstrated by Crist et al. (2009) [28]. So, abdominal fat mass may induce a greater degree of oxidative stress than overall fat mass, but no study has been conducted in the SLE population. We certainly found a regular association $(\mathrm{r}=0.337 \mathrm{p}=0.022)$ between $\mathrm{W} / \mathrm{H}$ ratio and DD $(\%)$ in our sample (both groups), which corroborates the studies cited. Family number refers to socioeconomic status, and it will be discussed later on. No stratification was performed for gender since there were just two males per group.

Lifestyle features are shown in Table 2. There is no significant difference regarding physical activity between the groups. This fact is important because exercise may influence oxidative stress status [29]. On the other hand, information about the type of physical exercise as well as its duration and its frequency was not collected. A significant difference concerning alcohol consumption was found, with $44 \%$ of the control group being social drinkers against $12 \%$ of the SLE group. Nevertheless, the SLE group had a greater state of oxidative stress than the control, which highlights the possible association of this condition with the disease. Other demographic features are reported in Table 3 . Significant differences can be observed between the groups concerning occupation $(\mathrm{p}=$ $0.011)$, household income $(\mathrm{p}=0.001)$ and education $(\mathrm{p}=$ $0.001)$. This difference between groups is relevant, be-

Table 1. Demographic and anthropometric features and DD in SLE and controls.

\begin{tabular}{cccc}
\hline Parameters & $\begin{array}{c}\text { Control } \\
(\mathrm{n}=25) \\
\text { Mean } \pm \mathrm{SD}\end{array}$ & $\begin{array}{c}\text { SLE } \\
(\mathrm{n}=25) \\
\text { Mean } \pm \mathrm{SD}\end{array}$ & $\begin{array}{c}\text { Significance } \\
\text { p-value }\end{array}$ \\
\hline Age (years) & $33.04 \pm 8.99$ & $32.76 \pm 8.86$ & 0.912 \\
BMI $\left(\mathrm{kg} / \mathrm{m}^{2}\right)$ & $25.87 \pm 7.58$ & $24.84 \pm 5.92$ & 0.595 \\
DD $(\%)$ & $33.47 \pm 3.67$ & $44.71 \pm 8.46$ & $0.000^{*}$ \\
WC $(\mathrm{cm})$ & $90.64 \pm 18.79$ & $91.41 \pm 14.24$ & 0.872 \\
HC $(\mathrm{cm})$ & $105.10 \pm 14.59$ & $101.02 \pm 11.36$ & 0.303 \\
W/H ratio & $0.85 \pm 0,065$ & $0.89 \pm 0.054$ & $0.048^{*}$ \\
Family numbers & $3.21 \pm 1.28$ & $4.00 \pm 1.06$ & $0.044^{*}$ \\
SLEDAI & N/A & $3.64 \pm 3.25$ & N/A \\
\hline
\end{tabular}

"Significantly different at $\mathrm{p}<0.05$ from the corresponding value in control group. BMI, body mass index; DD, damage index percentage; WC, waist circumference; $\mathrm{HC}$, hip circumference; $\mathrm{W} / \mathrm{H}$ ratio, waist/hip circumference ratio; N/A, not applicable. 
Table 2. Lifestyle features in SLE and controls.

\begin{tabular}{cccccc}
\hline \multirow{2}{*}{ Parameters } & \multicolumn{2}{c}{$\begin{array}{c}\text { Control } \\
(\mathrm{n}=25)\end{array}$} & \multicolumn{2}{c}{$\begin{array}{c}\text { SLE } \\
(\mathrm{n}=25)\end{array}$} & \multirow{2}{*}{$\begin{array}{c}\text { Significance } \\
\mathrm{p} \text {-value }\end{array}$} \\
\cline { 2 - 4 } & $\mathrm{N}(\%)$ & \multicolumn{2}{c}{$\mathrm{N}(\%)$} & \\
\cline { 2 - 5 } $\begin{array}{c}\text { Yesial } \\
\text { drinker }\end{array}$ & $11(44 \%)$ & $14(56 \%)$ & $3(12 \%)$ & $22(88 \%)$ & $0.012^{*}$ \\
$\begin{array}{c}\text { Physical } \\
\text { activity }\end{array}$ & $12(48 \%)$ & $13(52 \%)$ & $11(44 \%)$ & $14(56 \%)$ & 0.777 \\
\hline
\end{tabular}

*Significantly different at $\mathrm{p}<0.05$ from the corresponding value in control group.

Table 3. Demographic features in SLE and controls.

\begin{tabular}{|c|c|c|c|c|}
\hline Parameters & & $\begin{array}{c}\text { Control } \\
(\mathrm{n}=25) \\
\mathrm{N}(\%)\end{array}$ & $\begin{array}{c}\text { SLE } \\
(\mathrm{n}=25) \\
\mathrm{N}(\%)\end{array}$ & $\begin{array}{l}\text { Significance } \\
\text { p-value }\end{array}$ \\
\hline \multirow{3}{*}{ Civil status } & Single & $16(64 \%)$ & $14(56 \%)$ & \multirow{3}{*}{0.553} \\
\hline & Married & $9(36 \%)$ & $10(40 \%)$ & \\
\hline & Divorced & $0(0 \%)$ & $1(4 \%)$ & \\
\hline \multirow{6}{*}{ Occupation } & Employed & $16(64 \%)$ & $13(52 \%)$ & \multirow{6}{*}{$0.011^{*}$} \\
\hline & Unemployed & $0(0 \%)$ & $2(4 \%)$ & \\
\hline & $\begin{array}{l}\text { Works in the } \\
\text { home }\end{array}$ & $0(0 \%)$ & $6(24 \%)$ & \\
\hline & Student & $3(12 \%)$ & $1(4 \%)$ & \\
\hline & $\begin{array}{l}\text { Employed and } \\
\text { student }\end{array}$ & $6(24 \%)$ & $1(4 \%)$ & \\
\hline & $\begin{array}{l}\text { Forced out of } \\
\text { work }\end{array}$ & $0(0 \%)$ & $2(8 \%)$ & \\
\hline \multirow{6}{*}{$\begin{array}{l}\text { Household } \\
\text { income }\end{array}$} & Up to 1 min wage & $1(4 \%)$ & $4(16 \%)$ & \multirow{6}{*}{$0.001^{*}$} \\
\hline & 1 - 2 min wage & $2(8 \%)$ & $10(40 \%)$ & \\
\hline & 2 - 5 min wage & $5(20 \%)$ & $9(36 \%)$ & \\
\hline & $5-10$ min wage & $6(24 \%)$ & $2(8 \%)$ & \\
\hline & $10-20$ min wage & $6(24 \%)$ & $0(0 \%)$ & \\
\hline & $\begin{array}{c}\text { More than } 20 \mathrm{~min} \\
\text { wage }\end{array}$ & $5(20 \%)$ & $0(0 \%)$ & \\
\hline \multirow{4}{*}{ Education } & Primary school & $0(0 \%)$ & $9(36 \%)$ & \multirow{4}{*}{$0.001^{*}$} \\
\hline & Secondary school & $12(48 \%)$ & $13(52 \%)$ & \\
\hline & Undergraduate & $7(28 \%)$ & $3(12 \%)$ & \\
\hline & Postgraduate & $6(24 \%)$ & $0(0 \%)$ & \\
\hline \multirow{3}{*}{ Skin color } & White & $14(56 \%)$ & $10(40 \%)$ & \multirow{3}{*}{0.209} \\
\hline & Mixed & $7(28 \%)$ & $13(52 \%)$ & \\
\hline & Black & $4(16 \%)$ & $2(8 \%)$ & \\
\hline
\end{tabular}

*Significantly different at $\mathrm{p}<0.05$ from the corresponding value in control group.

cause lower socioeconomic status is associated with higher oxidation and lower levels of antioxidant nutrients [7]. Therefore, lower socioeconomic status can increase the imbalance of oxidant/antioxidant state. The influence of low socioeconomic status on oxidative stress may be explained through increased exposure to environmental toxins, such as hazardous wastes and pollution at home and at work [7].

No correlation $(r=0.046)$ was observed between BMI and DD (\%), although obesity is associated with a state of oxidative stress in the regular population [27,30]. Besides, obesity is common in patients with SLE, being independently associated with increased inflammation markers [31], so it may favor oxidative stress increases in patients with SLE and metabolic syndrome [4]. This relationship may not have been found because of the small and specific sample of SLE patients without any other chronic disorders. It is noteworthy that the current study is a pioneer in assessing oxidative stress by comet assay. All the other studies evaluated this state in other ways, including through urinary levels of 8 -epi-PGF2 $\alpha$ [27], lipid and protein oxidation and nitrogen oxide levels [4], plasma levels of thiobarbituric acid reactive substance (TBARS) [30], urinary levels of isoprostanes [32] and blood levels of malondialdehyde (MDA) and sulfhydryl groups ( $\mathrm{SH}$ ) [9].

No correlation was found between SLEDAI and DD $(\%)(\mathrm{r}=0.04)$, possibly because all patients in this study had non-active or mild SLE activity (mean $3.64 \pm 3.25$, minimum SLEDAI 0 and maximum 10). Hassan et al. (2011) [3] have found a correlation between markers of oxidative stress (malondialdehyde-MDA, glutathioneGSH and glutathione peroxidase-GSHPx) and disease activity in SLE patients. Wang et al. (2010) [5] found a strong response of oxidative/nitrosative stress markers in patients with higher SLEDAI, there were two groups: one with SLEDAI $<6$ and other with SLEDAI $\geq 6$, but they did not mention the maximum of their sample's disease activity. However, Lozovoy et al. (2011) [4] analyzed lipid and protein oxidation and nitrogen oxide levels and did not find this correlation. Their subjects presented a non-active or mild disease activity and paired BMI in control and SLE groups exactly as the present study. Another study also affirms that oxidative stress does not correlate with SLEDAI in patients with mild disease activity [32]. But this last study did not find a correlation between oxidative stress and objective markers of inflammation. Besides, Pérez et al. (2012) [9] did not report any correlation between disease activity and oxidative stress.

\section{CONCLUSION}

The positive correlation between $\mathrm{W} / \mathrm{H}$ ratio and DD (\%) suggests that abdominal fat reduction should be counseled to SLE patients in order to reduce oxidative stress. Lower socioeconomic status is another factor that can contribute to increase this state. DD (\%) was increased in SLE, which reflects the oxidant/antioxidant imbalance in 
these patients, independently of disease activity. These findings support an association between oxidative stress and SLE. This stronger correlation observed in patients with non-active or mild disease activity may be useful in elucidating the mechanisms of pathogenesis. Further studies are necessary to improve our understanding of these mechanisms.

\section{REFERENCES}

[1] Mathis, K., Venegas-Pont, M., Masterson, W., Stewart, N., Wasson, K. and Ryan, M. (2012) Oxidative stress promotes hypertension and albuminuria during autoimmune disease systemic lupus erythematosus. Hypertension, 59, 673-679.

doi:10.1161/HYPERTENSIONAHA.111.190009

[2] Grammatikos, A. and Tsokos, C. (2012) Immunodeficiency and autoimmunity: Lessons from systemic lupus erythematosus. Trends in Molecular Medicine, 18, 101108. doi:10.1016/j.molmed.2011.10.005

[3] Hassan, S., Gheita, T., Kenawy, S., Fahim, A., El-sorougy, I. and Abdou, M. (2011) Oxidative stress in systemic lupus erythematosus and arthritis patients: Relationship to disease manifestations and activity. International Journal of Rheumatic Diseases, 14, 325-331. doi:10.1111/j.1756-185X.2011.01630.x

[4] Lozovoy, M., Simão, A., Panis, C., Rotter, M., Reiche, E., Morimoto, H., Lavado, E., Cecchini, R. and Dichi, I. (2011) Oxidative stress is associated with liver damage, inflammatory status, and corticosteroid therapy in patients with systemic lupus erythematosus. Lupus, 20, 1250-1259. doi: $10.1177 / 0961203311411350$

[5] Wang, G., Pierangeli, S., Papalardo, E., Ansari, G. and Khan, M. (2010) Markers of oxidative and nitrosative stress in systemic lupus erythematosus: Correlation with disease activity. Arthritis \& Rheumatism, 62, 2064-2072.

[6] Kyttaris, V. (2010) Systemic lupus erythematosus: From genes to organ damage. Methods in Molecular Biology, 662, 265-283. doi:10.1007/978-1-60761-800-3_13

[7] Janicki-Deverts, D., Cohen, S., Matthews, K., Gross, M. and Jacobs, D. (2009) Socioeconomic status, antioxidant micronutrients, ad correlates of oxidative damage: The coronary artery risk development in young adults (CARDIA) study. Psychosomatic Medicine, 71, 541-548. doi:10.1097/PSY.0b013e31819e7526

[8] Bayir, H. and Kagan, V. (2008) Bench-to-bedside review: Mitochondrial injury, oxidative stress and apoptosis: There is nothing more practical than a good theory. Critical Care, 12, 206. doi:10.1186/cc6779

[9] Pérez, Y., Pérez, L., Netto, R., Lima, D. and Lima, E. (2012) Malondialdehyde and the sulfhydryl groups as biomarkers of oxidative stress in patients with systemic lupus erythematosus. Revista Brasileira de Reumatologia, 52, 656-660.

[10] Zhang, Q., Ye, D., Chen, G. and Zheng, Y. (2010) Oxidative protein damage and antioxidant status in systemic lupus erythematosus. Clinical and Experimental Dermatology, 35, 287-294. doi:10.1111/j.1365-2230.2009.03437.x

[11] Kurien, B. and Scofield, R. (2003) Free radical mediated peroxidative damage in systemic lupus erythematosus. Life Sciences, 73, 1655-1666. doi:10.1016/S0024-3205(03)00475-2

[12] Rastmanesh, R. and Baer, A. (2011) Possible augmentation of photosensitivity by dietary fuanocoumarins in patients with systemic lupus erythematosus. Lupus, 20, 10051009. doi:10.1177/0961203311414099

[13] Kotani, K. and Taniguchi, N. (2012) Correlation between high-sensitivity c-reactive protein and reactive oxygen metabolites during a one-year period among asymptomatic subjects. Journal of Clinical Medicine and Research, 4, 52-55.

[14] Ostling, O. and Johanson, K. (1984) Microeletrophoretic study of radiation-indeced DNA damages in individual mammalian cells. Biochemical and Biophysical Research Communications, 123, 291-298. doi:10.1016/0006-291X(84)90411-X

[15] Singh, N., McCoy, M., Tice, R. and Schneider, E. (1988) A simple technique for quantitation of levels of DNA damage in individual cells. Experimental Cell Research, 175, 184-191. doi:10.1016/0014-4827(88)90265-0

[16] Fairbairn, D., Olive, P. and O'Neill, K. (1995) The comet assay: A comprehensive review. Mutation Research, 339, 37-59. doi:10.1016/0165-1110(94)00013-3

[17] Collins, A.R. (2009) Investigating oxidative DNA damage and its repair using the comet assay. Mutation Research, 681, 24-32.

[18] Andreoli, C., Leopardi, P., Rossi, S. and Crebelli, R. (1999) Processing of DNA damage induced by hydrogen peroxide and methyl methanesulfonate in human lymphocytes: Analysis by alkaline single cell gel electrophoresis and cytogenetic methods. Mutagenesis, 14, 497-503.

[19] Dusinska, M. and Collins, A.R. (2008) The comet assay in human biomonitoring: Gene-environment interactions. Mutagenesis, 23, 191-205.

[20] McKenna, D.J., Stephanie, R., McKeown, S.R. and McKelvey-Martin, V.J. (2008) Potential use of the comet assay in the clinical management of cancer. Mutagenesis, 23, 183-190.

[21] Bombardier, C., Gladman, D., Urowitz, M., Caron, D. and Chang, C. (1992) Derivation of the SLEDAI: A disease activity index for lupus patients. The Committee on prognosis studies in SLE. Arthritis \& Rheumatism, 35, 630-640. doi:10.1002/art.1780350606

[22] Hochberg, M., et al. (1997) Updating the american college of rheumatology revised criteria for the classification of systemic lupus erythematosus. Arthritis \& Rheumatism, 40, 1725. doi:10.1002/art.1780400928

[23] Miranda-Vilela, A., Akimoto, A., Alves, P., Pereira, L., Gonçalves, C., Klautau-Guimarães, M. and Grisolia, C. (2009) Dietary carotenoid-rich pequi oil reduces plasma lipid peroxidation and DNA damage in runners and evidence for an association with MnSOD genetic variantVa19Ala. Genetics and Molecular Research, 8, 1481-1495. doi:10.4238/vol8-4gmr684

[24] Miranda-Vilela, A., Alves, P., Akimoto, A., Pereira, L., 
Klautau-Guimara, M. and Grisolia, C. (2010) The effect of hydrogen peroxide-induced oxidative stress on leucocytes depends on age and physical training in healthy human subjects carrying the same genotypes of antioxidant enzymes' gene polymorphisms. American Journal of Human Biology, 22, 807-812. doi:10.1002/ajhb.21086

[25] Collins, A.R., Aiguo, M. and Duthie, S.J. (1995) The kinetics of oxidative DNA damage (strand breaks and oxidised pyrimidines) human cells. Mutation Research, 336, 69-77.

[26] Jalonszynski, P., Kujawski, M., Czub-Swierczek, M., Markowska, J. and Szyfter, K. (1997) Bleomicin-induced DNA damage and its removal in lymphocytes of breast cancer patients studied by comet assay. Mutation Research, 385, 223-233.

[27] Keaney, J., Lasson, M., Vasan, R., Wilson, P., Lipinska, I., Corey, D., Massaro, J., Sutherland, P., Vita, J. and Benjamin, E. (2003) Obesity and systemic oxidative stress clinical correlates of oxidative stress in the Framinghan study. Arteriosclerosis, Thrombosis and Vascular Biology, 23, 434-439. doi:10.1161/01.ATV.0000058402.34138.11

[28] Crist, B., Alekel, L., Ritland, L., Hanson, L., Genschel, U. and Reddy, M. (2009) Association of oxidative stress, iron, and centralizes fat mass in healthy postmenopausal women. Journal of Women's Health, 18, 795-801. doi:10.1089/jwh.2008.0988

[29] Florencio, G., Gonçalves, A., Canário, A. and Silva, M. (2011) Aging: A reflection about physical activity and oxidative stress in woman. Acta Médica Portuguesa, 4, 983-988.

[30] Furukawa, S., Fujita, T., Shimabukuro, M., Iwaki, M., Yamada, Y., Nakajima, Y., Nakayama, O., Makishimo, M., Matsuda, M. and Shimomura, I. (2004) Increased oxidative stress in obesity and its impact on metabolic syndrome. The Journal of Clinical Investigation, 114, 17521761.

[31] Oeser, A., Chung, C., Asanuma, Y., Avalos, I. and Stein, M. (2005) Obesity is a independent contributor to functional capacity and inflammation in systemic lupus erythematosus. Arthritis \& Rheumatism, 52, 3651-3659. doi:10.1002/art.21400

[32] Avalos, I., Chung, C., Oeser, A., et al. (2007) Oxidative stress in systemic lupus erythematosus: Relationship to disease activity and symptoms. Lupus, 16, 195-200. 